Sharif University of Technology
Scientia Iranica
Transactions E: Industrial Engineering
hCIttp://scientiairanica.sharif.edu
IRAN I CA

\title{
Imperfect production in three-layer supply chain systems incorporating deterioration and screening effect
}

\author{
S. Adak and G.S. Mahapatra* \\ Department of Mathematics, National Institute of Technology Puducherry, Karaikal-609609, India.
}

Received 5 July 2019; received in revised form 22 June 2020; accepted 18 October 2020

\section{KEYWORDS}

Three-layer supply

chain;

Defective items;

Deterioration;

Production;

Cost for idle time;

Screening.

\begin{abstract}
This paper develops a three-layer supply chain for defective and non-defective types of produced items by supplier and manufacturer. The condition set by the chain for the suppliers and manufacturers is that after completion of screening, defective items are sold to the supplier to produce other items using the mentioned items. In the subsequent stage, the retailer accepts the non-defective items produced and screened by the manufacturer. Hence, although the retailers receive items of perfect quality for selling to the customers, they consider the effect of the deterioration of items. This model also considers the impact of several business strategies such as optimal order size of raw materials, production rate, unit production cost, idle time costs of the supplier, manufacturers in a collaborative marketing system, etc. to determine the optimum average profit of the integrated model. This study discusses the selling price of the retailer, demand rate of the customer, purchase cost of supplier, and holding cost, which can be a significant breakthrough in expanding the profit of the business in real terms. Numerical examples and sensitivity analysis are presented to illustrate the phenomenon of theoretical study and demonstrate the managerial implication of the model.
\end{abstract}

(C) 2022 Sharif University of Technology. All rights reserved.

\section{Introduction}

Supply chain management is a consistent progress in which an organization manages the flow of products, services, money, etc. A Supply Chain Model (SCM) is a network of suppliers, manufacturers, retailers, and customers to obtain the maximum profit with minimum costing for fulfilling customer demand. As per the facts, the SCM includes the movement and storage of raw materials from nature, supply of raw materials, screening of raw materials, buyback/return policies, transportation of raw materials into a manufacturer warehouse, production of goods at the production

\footnotetext{
*. Corresponding author.

E-mail addresses: sudip133@yahoo.co.in (S. Adak); gs.mahapatra@nitpy.ac.in (G.S. Mahapatra)
}

center, screening of finished goods, and distribution of these finished products to retailers for sale to the customers. A single supplier and single customer problems were developed by researchers [1-6] for the integrated production inventory problem. However, it is highly imperative that a systematic network is created among suppliers, manufacturer, retailers, and customers. Thus, in this case, a three-layer supplier chain is considered into our model.

One of the key assumptions of the classical Economic Order Quantity (EOQ) model is that the items produced and received are of perfect quality. However, in reality, production is not always accurate; hence, there is a need to incorporate the defective items. This paper develops a supply chain for supplier, manufacturer, and retailer considering the defective and non-defective types of produced items. This model also considers the impact of several business strategies such as optimal order size of raw materials, production 
rate, unit production cost, idle costs of supplier, and manufacturer in a collaborating marketing system and determines the optimum average profit of the integrated model. The supply chain considers the condition that defective items would be sent back to supplier after screening to repair/produce other items using these defective items for the manufacturer. The manufacturer produces items including perfect and defective items, but only perfect items are supplied to the retailer after screening. In addition, defective items are sent back to the supplier of the retailer. Thereupon, the retailer receives perfect-quality items for selling to the customers, but considers the effect of deterioration.

Deterioration means decay or spoilage of the item; thereafter, the effect of the deterioration of the items in the lot size must be taken into account. For items such as steel, hardware, glassware, and toys, the rate of deterioration is too low; however, some items such as alcohol, gasoline, radioactive chemical, medicine, and food items deteriorate remarkably over time, hence the need for considering deterioration concept. In this paper, a three-layer SCM is proposed with imperfect production quality for supplier and manufacturer. There are very few pieces of the literature that studied a three-layer supply chain with deterioration. The proposed supply chain system considers constant deterioration of an item at the retailer end without any replacement of items of the deteriorated items.

This paper presents mathematical modeling and analysis of supply chain systems without shortages and cost of the idle time at the supplier and the manufacturer. The production rate of supplier and manufacturer is greater than the demand rate of manufacturer and retailer, respectively. The unit production cost of the modeling is a function of production rate. Uniform distribution functions for production of defective items have been considered along with simultaneously carrying out the screening process with a rate less than, or equal to, the production rate, but higher than or equal to the demand rate.

In this study, the production-based supply chain system has these advantages:

(i) For the supplier, the defective items are sent back to the supplier at one lot with the sales price. Thus, the faulty items can be used by the supplier to prepare another product or can sell at a few percentages of the selling price;

(ii) For the manufacturer, the defective items are sent back to the supplier which can be sold at the rate of a few portions of the selling price to recover some profit due to defective of items;

(iii) The retailer receives the perfect-quality items for selling to the customer, which will help to improve their goodwill; (iv) In this SCM, it is easy to recognize the relationship between the demand rate of the retailer and the selling price of the retailer.

The organization of the rest of the paper is as follows: Section 2 describes the details of literature review which motivated us to study and adopt the proposed three-layer SCM. Section 3 describes the formulation of the SCM and mathematical computation based on the proposed production inventory. Section 4 presents the optimization of the proposed SCM. The example of the proposed three-layer SCM with a detailed numerical analysis is presented in Section 5. Section 6 presents sensitivity analysis for various parameters to illustrate the vital aspect of the model; further, the managerial implications are also discussed. Concluding remarks with limitations of this study and scope for future research on the three-layer SCM are given in Section 7 .

\section{Literature review}

This section focuses on reviewing the relevant literature of the three-layer supply chain with the production rate for supplier and manufacturer, selling price of the retailer, demand rate of the customer, and purchase cost of the supplier. With rapid changes and enlargement of the supply chain system business management, it is vital to construct a systematic network among suppliers, manufacturer, retailers, and customers. In accordance, in our model, we have considered a threelayer supplier chain. The literature of supply chain management has developed a lot during the last few decades [7,8]. Li et al. [9] constructed a single-retailer and two-supplier SCM.

AlDurgam et al. [10] developed a single-vendor and single-manufacturer integrated inventory model with stochastic demand and variable production rate. Pasandideh et al. [11] discussed vendor-managed inventory in the joint replenishment problem of a multi-product single-supplier multiple-retailer supply chain. Several researchers [12-25] constructed an integrated production model consisting of multi-stage supply chain systems. Ben-Daya and Seliaman [26] developed an inventory model in a three-layer SCM with raw material replenishment. Several researchers [27,28] developed a fuzzy dynamic multiobjective multi-item model by considering customer satisfaction in the supply chain. Taleizadeh and Noori-Daryan [29] studied the pricing, manufacturing, and inventory policies for raw materials in the threelevel supply chain. Gamasaee and Fazel Zarandi [30] discussed incorporating demand, orders, lead time, and pricing decisions for reducing the bullwhip effect in supply chains. Taleizadeh et al. [31] developed a sustainable closed-loop supply chain problem with pricing decisions and discounts on returned products. 
The screening process has been used to separate the perfect-quality products from the whole batch of the produced items. After the screening process, the non-defective items are supplied to the supplier. Recently, some existing research articles have explored the issue of imperfect-quality items, which are of practical importance. Thereafter, EOQ models [3244] were developed for items with imperfect quality. Pal et al. [45] constructed a three-layer supply chain EPQ model for price-and stock-dependent stochastic demand with the imperfect items under rework. Pal et al. [46] represented a three-layer SCM for reworkable items. Jian et al. [47] presented a three-echelon reverse supply chain for economic incorporation of coordination strategies and social benefit. Pal et al. [48] developed a manufacturing-oriented SCM for imperfect quality with inspection errors, stochastic demand under rework, and shortages. Khan et al. [49] presented an optimal vendor-buyer inventory policy by accounting for quality inspection errors of imperfect items at the buyer's end. Feng et al. [50] discussed pricing and lot-sizing policies for perishable goods when the demand depends on selling price, displayed stocks, and expiration date.

Deterioration of the items in the inventory model is inevitable. In reality, we cannot neglect the effect of deterioration. Dye [51] developed a finite horizon deteriorating inventory model of two-phase pricing with time-dependent demand and cost under trade credit financing. Chung and Cárdenas-Barrón [52] presented a simplified solution procedure for deteriorating items under stock-dependent demand and two-level trade credit in the supply chain management. Gao et al. [53] presented a two-layer supply chain system with stochastic customer demand and delayin-payment. Chan et al. [54] developed an integrated production inventory model for deterioration during delivery. Tiwari et al. [55] constructed an optimal pricing and lot-sizing policy for supply chain systems with deteriorating items under limited storage capacity. Liao et al. [56] developed a lot-size model with deterioration for two warehouses under order-sizedependent trade credit. Chung et al. [57] developed an inventory model with non-instantaneous and exponential deterioration for an integrated three-layer supply chain under two levels of trade credit. Inventory model [58,59] was studied for deteriorating items with expiration dates and partial backlogging in two layers. Puga et al. [60] proposed a supply chain system for facility location, safety stock placement, and delivery strategy with time preferences for two customer classes. Modak and Kelle [61] presented a dualchannel supply chain under price and delivery-time dependent stochastic customer demands incorporating the price and order quantity for retailers. Tiwari et al. [62] discussed retailer's optimal ordering policy for deteriorating items under order-size-dependent trade credit and complete backlogging. Adak and Mahapatra [63] developed the effect of reliability on multi-item inventory systems with shortages and partial backlog incorporating time-dependent demand and deterioration. Bhunia et al. [64] studied a single deteriorating item with variable demand dependent on marketing strategy and displayed stock level. Teimoury and Kazemi [65] studied integrated pricing and inventory model for deteriorating products in a twostage supply chain under replacement and shortage.

\section{Formulation of three layer SCM}

This paper develops an SCM of production inventory, considering that the production rate of supplier and production rate of (a decision variable) manufacturer are greater than the demand rate of manufacturer and retailer, respectively. The proposed study also considers the start time of production at the supplier and the manufacturer to be initiated in such a way that the shortages would not occur. The SCM considers unit production cost as a function of production rate. We also consider the cost of idle times for supplier and manufacturer. This production inventory-based supply chain system proposes that the produced defective items of supplier and manufacturer follow uniform distribution, i.e., $f(x)=\frac{1}{b-a}, a<x<b$.

Hence, the screening process has been carried out simultaneously during the production period. It further considers that the screening rate is greater than or equal to the demand rate, but less than or equal to the production rate. The proposed supply chain system considers the deterioration of an item to be constant due to time or transit, and there is no repair or replenishment of the deteriorated items. The proposed study is very much interesting due to the nature of the system and the real-life practical application of the concept.

\subsection{Notation}

The proposed SCM will be developed using the following notations:

$A_{s}, A_{m}, A_{r} \quad$ Setup cost of the supplier, manufacturer, and retailer, respectively

$H_{s}, H_{m}, H_{r} \quad$ Unit holding cost per unit time for supplier, manufacturer and retailer, respectively

$W_{s}, W_{m}, W_{r}$ Selling price per unit of non-defective items for supplier, manufacturer, and retailer, respectively

$A P_{S}, A P_{M}, \quad$ Average profit of the supplier, $A P_{R} \quad$ manufacturer, and retailer, respectively

$P_{s}, P \quad$ Production rate for the supplier and manufacturer (i.e., demand rate at supplier), respectively 
$R_{s}, R_{m} \quad$ Screening rate per unit time for supplier and manufacturer, respectively

$S_{s}, S_{m} \quad$ Screening cost per unit item for supplier and manufacturer, respectively

$I_{s}, I_{m} \quad$ Cost per unit idle time of supplier and manufacturer, respectively

$D_{r}, D_{c} \quad$ Demand rate of the retailer and customers, respectively

$\alpha, \beta \quad$ Probability of defective items for supplier and manufacturer, respectively

$R \quad$ Initial stock level of supplier

$C_{s} \quad$ Purchasing cost per unit item of supplier

$S_{p} \quad$ Selling price per unit defective item of supplier

$M_{p} \quad$ Selling price per unit defective item of manufacturer

$\delta_{m} \quad$ Cost per unit finished product

$\theta \quad$ Deterioration rate of finished items

$d_{c} \quad$ Cost of each deteriorated item

$L \quad$ Total labor/energy costs per unit time of a production system

$\gamma \quad$ Tool costs per unit of the production rate

$E(x) \quad$ Expectation of variable $x$

$T \quad$ Cycle length of retailer

\subsection{Production inventory-based three-layer $S C M$}

The proposed SCM consists of three stages of economic production lot-sizing model for a single supplier, a manufacturer, and a retailer. Let the production rate of raw materials be $P_{s}$ with nondefective as well as defective items. After completion of screening, the non-defective items are supplied to the manufacturer at rate $P$ up to time $t_{1}$, and the defective items are sent back at one lot with sales price $S_{p}$ per unit item. The manufacturer produces the item at rate $P$ and meets the demand of retailer at a rate $D_{r}$ up to time $t_{2}$. The manufacturer produces both defective as well as non-defective items. After completion of screening, the defective items accumulated at time $t_{1}$ are sold at the rate of $M_{p} \%$ of selling price per unit of the non-defective item at the manufacturer end. Thus, the retailer receives the perfect-quality items for selling to the customer at rate $D_{c}$ up to time $t_{2}$. In retailer warehouse, many items deteriorate over time. Figures 1 and 2 represent the pictorial representation and graphical representation, respectively, in a threelayer SCM with deterioration.

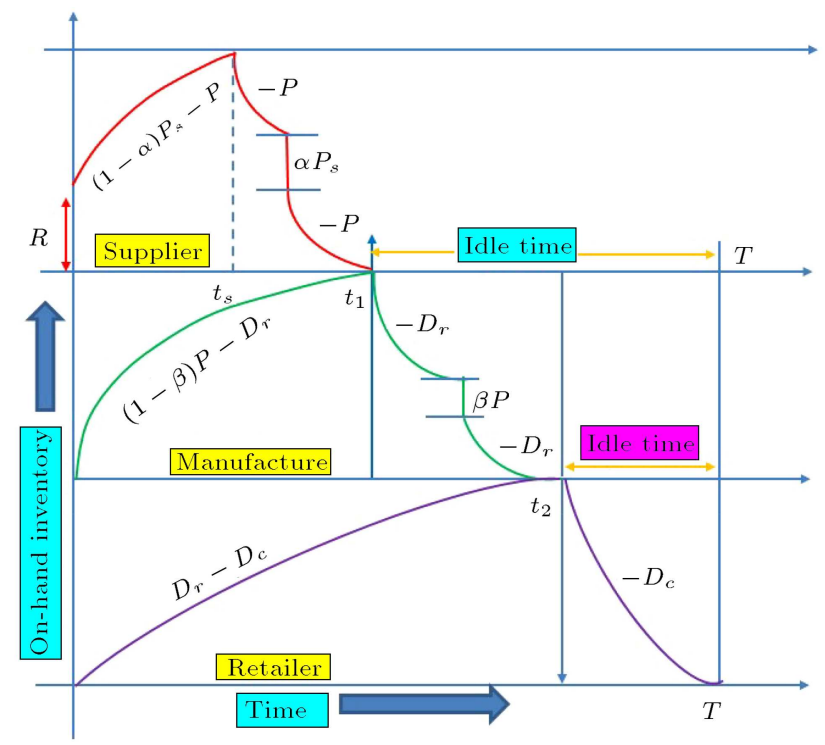

Figure 2. Graphical representation of the three-layer supply chain.

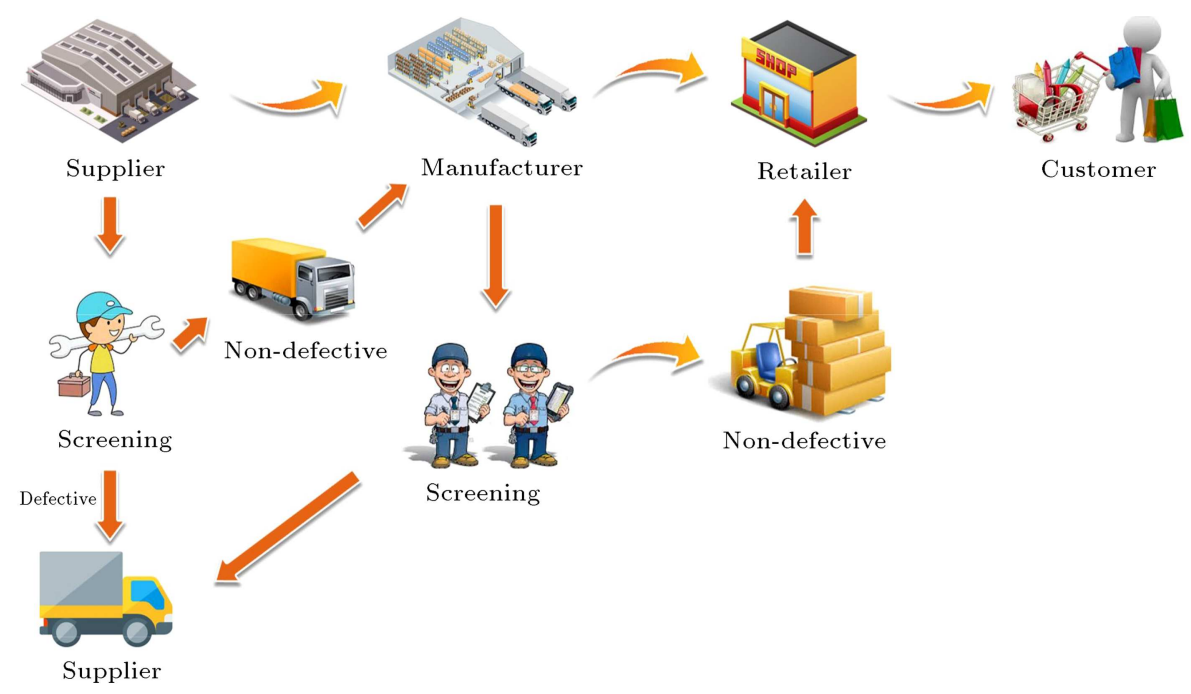

Figure 1. Pictorial representation of the three-layer supply chain model. 


\subsection{Formulation of supplier individual cost}

Let $q_{s}(t)$ be the inventory of non-defective items and $R$ be the initial stock $(t=0)$ for the supplier. The supplier starts the production at the rate $P_{s}$ unit per unit time and supplies it to the manufacturer. At $t=t_{s}$, suppliers stop their production and at $t=t_{1}$, the inventory level becomes zero. The lot size $R$ and the items produced by the supplier for run time $t_{s}$ are screened with rate $R_{s}$ at cost $S_{s}$ per unit item. After completion of screening, the defective items are sold to the supplier at a price $S_{p}$ per unit item. Then, the differential equations for the supplier, as shown in Figure 3, during [0,T] are given by:

$$
\frac{d q_{s}(t)}{d t}= \begin{cases}(1-\alpha) P_{s}-P, & \text { for } 0 \leq t \leq t_{s} \\ -P, & \text { for } t_{s} \leq t \leq t_{1} \\ 0, & \text { for } t_{1} \leq t \leq T\end{cases}
$$

with the boundary conditions are $q_{s}(0)=(1-\alpha) R$ and $q_{s}\left(t_{1}\right)=0$.

The solution of the above differential equations using the boundary conditions $q_{s}(0)=(1-\alpha) R$ and $q_{s}\left(t_{1}\right)=0$ is:

$$
q_{s}(t)=\left\{\begin{array}{ccc}
\left\{(1-\alpha) P_{s}-P\right\} t & & \\
+(1-\alpha) R, & \text { for } & 0 \leq t \leq t_{s} \\
P\left(t_{1}-t\right), & \text { for } \quad t_{s} \leq t \leq t_{1}
\end{array}\right.
$$

Lemma 1. The suppliers stop their production at time $t_{s}=\frac{1}{P_{s}}\left(\frac{P t_{1}}{1-\alpha}-R\right)$ when the inventory level becomes zero at time $t_{1}$ and defective items at supplier be $\alpha$.

Proof. The inventory of supplier for $t$ is given by Eq. (2). Satisfying the condition of $q_{s}(t)$ at time $t=t_{s}$, we obtain:

$$
q_{s}(t)=\left\{(1-\alpha) P_{s}-P\right\} t_{s}+(1-\alpha) R .
$$

Again, the inventory level at $t=t_{s}$ is $q_{s}(t)=P\left(t_{1}-t_{s}\right)$.

Therefore, by satisfying the condition of $q_{s}(t)$ at $t_{s}$, a relation is obtained as follows:

$$
\left\{(1-\alpha)_{P_{s}}-P\right\} t_{s}+(1-\alpha) R=P\left(t_{1}-t_{s}\right) .
$$

The time to stop the production by the supplier is given by:

$$
t_{s}=\frac{1}{P_{s}}\left(\frac{P t_{1}}{1-\alpha}-R\right) .
$$

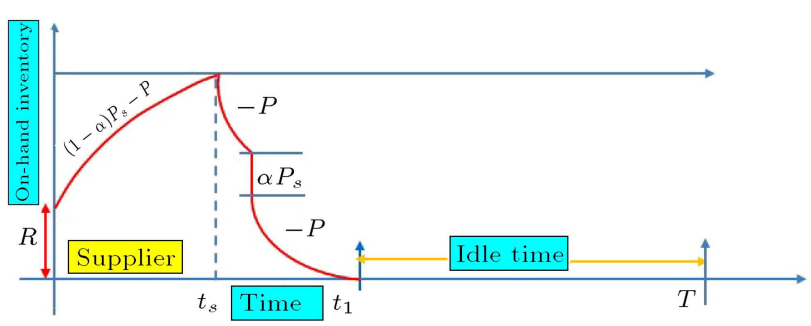

Figure 3. Sketch for the inventory level of supplier.
The holding cost of non-defective items during $\left(0, t_{1}\right)$ is:

$$
\begin{gathered}
H_{s} \int_{0}^{t_{1}} q_{s}(t) d t=\frac{H_{s}}{2}\left[P t_{1}^{2}+\frac{1}{P_{s}}\left\{2 R P t_{1}\right.\right. \\
\left.\left.-\frac{P^{2} t_{1}^{2}}{1-\alpha}-R^{2}(1-\alpha)\right\}\right]
\end{gathered}
$$

The holding cost of defective items during $\left(0, t_{s}\right)$ is:

$$
\begin{gathered}
H_{s} \int_{0}^{t_{s}} \alpha P_{s}\left(t_{s}-t\right) d t+\alpha R \frac{R}{R_{s}}+\alpha P_{s} t_{s} \frac{P_{s}}{R_{s}} \\
=\alpha H_{s}\left[\frac{1}{2 P_{s}}\left(\frac{P t_{1}}{1-\alpha}-R\right)^{2}+\frac{R^{2}}{R_{s}}\right. \\
\left.+\frac{P_{s}}{R_{s}}\left(\frac{P t_{1}}{1-\alpha}-R\right)\right] .
\end{gathered}
$$

The screening cost is:

$$
S_{s}\left(R+P_{s} t_{s}\right)=S_{s} \frac{P t_{1}}{1-\alpha} .
$$

The income from selling the non-defective and defective items of the supplier is:

$$
\begin{aligned}
& W_{s}(1-\alpha)\left(R+P_{s} t_{s}\right)+S_{p} \alpha\left(R+P_{s} t_{s}\right) \\
& \quad=P t_{1}\left(W_{s}+\frac{S_{p} \alpha}{1-\alpha}\right)
\end{aligned}
$$

The purchase cost of the supplier is:

$$
C_{s} R+C_{s} P_{s} t_{s}=C_{s} \frac{P t_{1}}{1-\alpha} .
$$

The fixed setup cost of the supplier is given by $A_{s}$. The idle cost for the supplier is:

$$
I_{s}\left(T-t_{1}\right) \text {. }
$$

Therefore, the average profit of supplier $\left(A P_{S}\right)$ is given by the following equation:

$$
\begin{aligned}
A P_{S} & =\frac{1}{T}\left[P t_{1}\left(W_{s}+\frac{S_{p} \alpha}{1-\alpha}-\frac{C_{s}+S_{s}}{1-\alpha}\right)-A_{s}\right. \\
& -\frac{H_{s}}{2}\left\{P t_{1}^{2}+\frac{1}{P_{s}}\left(2 R P t_{1}-\frac{P^{2} t_{1}^{2}}{1-\alpha}-R^{2}(1-\alpha)\right)\right\} \\
- & \alpha H_{s}\left\{\frac{1}{2 P_{s}}\left(\frac{P t_{1}}{1-\alpha}-R\right)^{2}+\frac{R^{2}}{R_{s}}\right. \\
+ & \left.\left.\frac{P_{s}}{R_{s}}\left(\frac{P t_{1}}{1-\alpha}-R\right)\right\}-I_{s}\left(T-t_{1}\right)\right]
\end{aligned}
$$




\subsection{Formulation of manufacturer individual cost}

Let $q_{m}(t)$ be the inventory of non-defective items of the manufacturer who start their production at the rate $P$ unit per unit time and supply the items to the retailer. At $t=t_{1}$, manufacturers stop their production; at $t=t_{2}$, the inventory level becomes zero. The items produced by the manufacture up to the production run time $t_{1}$ are screened with rate $R_{m}$ at cost $S_{m}$ per unit item. After completion of screening, the defective items are accumulated at time $t_{1}$ and are sold at $M_{p} \%$ of selling price per unit good item at the supplier. The differential equations as per Figure 4 for the manufacture at $[0, T]$ are given by:

$$
\frac{d q_{m}(t)}{d t}=\left\{\begin{array}{lll}
(1-\beta) P-D_{r} & \text { for } & 0 \leq t \leq t_{1} \\
-D_{r} & \text { for } & t_{1} \leq t \leq t_{2} \\
0 & \text { for } & t_{2} \leq t \leq T
\end{array}\right.
$$

with the boundary conditions being $q_{m}(0)=0$ and $q_{m}\left(t_{2}\right)=0$.

The solution of the above differential equations using the boundary conditions $q_{m}(0)=0$ and $q_{m}\left(t_{2}\right)=0$ is as follows:

$$
q_{m}(t)= \begin{cases}\left\{(1-\beta) P-D_{r}\right\} t & \text { for } \quad 0 \leq t \leq t_{1} \\ D_{r}\left(t_{2}-t\right) & \text { for } \quad t_{1} \leq t \leq t_{2}\end{cases}
$$

Lemma 2. The inventory level of the manufacturer becomes zero at time $t_{2}=\frac{(1-\beta) P t_{1}}{D_{r}}$, where at time $t_{1}$ the manufacture stop their production and $\beta$ is the occurrence probability for defective items at the manufacturer.

Proof. The inventory of the manufacturer at time $t$ is given by Eq. (12). The inventory level at $t_{1}$ is:

$$
q_{m}(t)=\left\{(1-\beta) P-D_{r}\right\} t_{1} .
$$

Again, the inventory level at $t=t_{1}$ is:

$$
q_{m}(t)=D_{r}\left(t_{2}-t_{1}\right) .
$$

Therefore, a relation satisfying the condition of $q_{m}(t)$ at $t_{1}$ is obtained as follows:

$$
\left\{(1-\beta) P-D_{r}\right\} t_{1}=D_{r}\left(t_{2}-t_{1}\right) .
$$

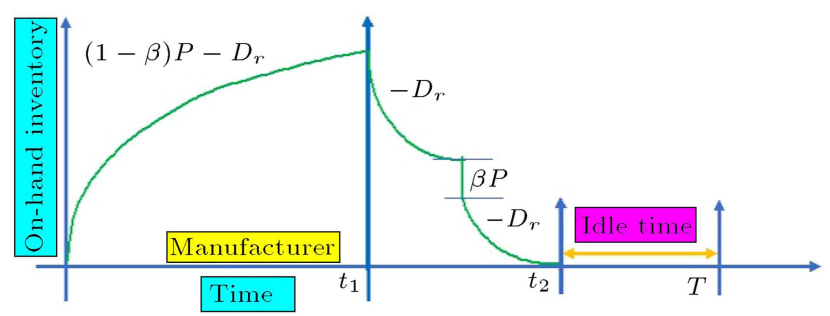

Figure 4. Sketch for the inventory level of manufacturer.
From the above expression, we get:

$$
t_{2}=\frac{(1-\beta) P t_{1}}{D_{r}} \text {. }
$$

The holding cost of non-defective items during $\left(0, t_{2}\right)$ is:

$$
H_{m} \int_{0}^{t_{2}} q_{m}(t) d t=\frac{H_{m}(1-\beta) P t_{1}^{2}}{2}\left\{\frac{(1-\beta) P}{D_{r}}-1\right\} .
$$

The holding cost of defective items during $\left(0, t_{1}\right)$ is:

$$
\begin{array}{r}
H_{m} \int_{0}^{t_{1}} \beta P\left(t_{1}-t\right) d t+\beta P t_{1} \frac{P}{R_{m}} \\
=H_{m} \beta P t_{1}\left(\frac{t_{1}}{2}+\frac{P}{R_{m}}\right) .
\end{array}
$$

The screening cost is:

$$
S_{m} P t_{1} \text {. }
$$

The income from selling the non-defective and defective items is:

$$
\begin{array}{r}
W_{m}(1-\beta) P t_{1}+M_{p} W_{m} \beta P t_{1} \\
=W_{m} P t_{1}\left(1-\beta+M_{p} \beta\right) .
\end{array}
$$

The total production cost is:

$$
\left(W_{s}+\delta_{m}+\frac{L}{P}+\gamma P\right) P t_{1}
$$

The setup cost of the manufacturer is fixed which is $A_{m}$. The idle cost for the manufacturer is:

$$
I_{m}\left(T-t_{1}\right) \text {. }
$$

Therefore, the average profit of the manufacturer $\left(A P_{M}\right)$ is given by:

$$
\begin{gathered}
A P_{M}=\frac{1}{T}\left[W_{m} P t_{1}\left(1-\beta+M_{p} \beta\right)-A_{m}-S_{m} P t_{1}\right. \\
-H_{m} P t_{1}\left\{\frac{(1-\beta)^{2} P t_{1}}{2 D_{r}}+\frac{\beta P}{R_{m}}+t_{1}\left(\beta-\frac{1}{2}\right)\right\} \\
\left.-\left(W_{s}+\delta_{m}+\frac{L}{P}+\gamma P\right) P t_{1}-I_{m}\left(T-t_{1}\right)\right]
\end{gathered}
$$

\subsection{Formulation of retailer individual cost}

After receiving the items from the manufacturer, $q_{r}(t)$ is an on-hand inventory for the retailer. The retailer starts its production at the rate $D_{r}$ unit per unit time and supplies it to the customer. At $t=t_{2}$, retailers stop their production and the inventory level becomes zero at $t=T$. The differential equations for the retailers per Figure 5 in $[0, T]$ are given by: 


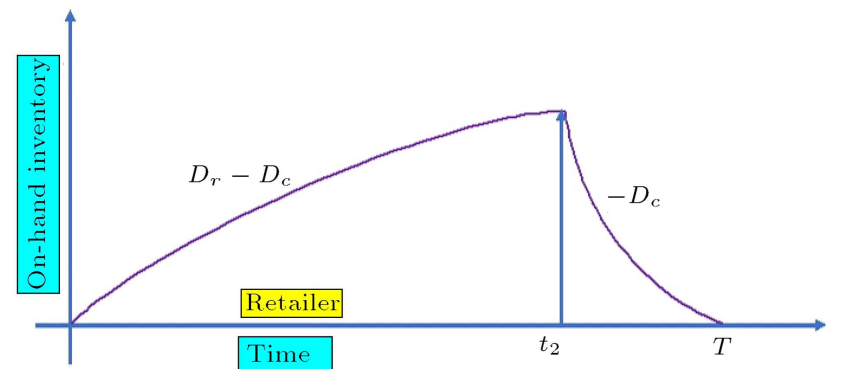

Figure 5. Diagram of inventory level of retailer.

$$
\frac{d q_{r}(t)}{d t}=\left\{\begin{array}{lll}
D_{r}-D_{c}-\theta q_{r}(t), & \text { if } & 0 \leq t \leq t_{2} \\
-D_{c}-\theta q_{r}(t), & \text { if } \quad t_{2} \leq t \leq T
\end{array}\right.
$$

with the boundary conditions being $q_{r}(0)=0$ and $q_{r}(T)=0$.

The solution of the above differential equations after applying the boundary conditions $q_{r}(0)=0$ and $q_{r}(T)=0$ is:

$$
q_{r}(t)= \begin{cases}\frac{1}{\theta}\left(D_{r}-D_{c}\right)\left(1-e^{-\theta t}\right), & \text { if } \quad 0 \leq t \leq t_{2} \\ \frac{D_{c}}{\theta}\left(e^{\theta(T-t)}-1\right), & \text { if } \quad t_{2} \leq t \leq T_{(22)}\end{cases}
$$

Lemma 3. The inventory level of retailer becomes zero at time $T=\frac{D_{r} t_{2}}{D_{c}}$, when the inventory level becomes zero at time $t_{2}$ for the manufacturer.

Proof. The inventory of the manufacturer for the time $t$ is given by Eq. (22). The inventory level at $t_{2}$ is:

$$
q_{r}(t)=\frac{1}{\theta}\left(D_{r}-D_{c}\right)\left(1-e^{-\theta t_{2}}\right)
$$

Again, the inventory level at $t=t_{2}$ is:

$$
q_{r}(t)=\frac{D_{c}}{\theta}\left(e^{\theta}\left(T-t_{2}\right)-1\right) .
$$

Therefore, a relation satisfying the condition of $q_{r}(t)$ at $t_{2}$ is obtained as follows:

$$
\frac{1}{\theta}\left(D_{r}-D_{c}\right)\left(1-e^{-\theta t_{2}}\right)=\frac{D_{c}}{\theta}\left(e^{\theta\left(T-t_{2}\right)}-1\right) .
$$

The above expression gives the time of inventory level vanishing at the retailer level as follows:

$$
T=\frac{D_{r} t_{2}}{D_{c}}
$$

The holding cost of items during $(0, T)$ is:

$$
H_{r} \int_{0}^{T} q_{r}(t) d t=\frac{H_{r}}{\theta}\left(D_{r} t_{2}-D_{c} T\right) .
$$

The deterioration cost of the retailer is:

$$
d_{c}\left(D_{r} t_{2}-D_{c} T\right)
$$

The income from selling the items is:

$$
W_{r} D_{c} T \text {. }
$$

The fixed setup cost of the retailer is $A_{r}$. The purchase cost of the retailer is:

$$
W_{m} D_{c} T
$$

Therefore, the average profit of the retailer $\left(A P_{R}\right)$ is given by:

$$
\begin{aligned}
A P_{R}= & \frac{1}{T}\left[\left(W_{r}-W_{m}+\frac{H_{r}}{\theta}+d_{c}\right) D_{c} T-A_{r}\right. \\
& \left.-\left(\frac{H_{r}}{\theta}+d_{c}\right)(1-\beta) P t_{1}\right] .
\end{aligned}
$$

\subsection{Expected integrated average profit of the $S C M$}

To find the Expected Integrated Average Profit (EIAP) of the proposed three-layer SCM, we have to determine the expected average profit for the supplier, manufacturer, and retailer.

Through Eq. (10), the expected average profit of the supplier is:

$$
\begin{aligned}
E A P_{S} & =\frac{1}{T}\left[P t _ { 1 } \left\{W_{s}+S_{p} E\left(\frac{\alpha}{1-\alpha}\right)\right.\right. \\
& \left.-\left(C_{s}+S_{s}\right) E\left(\frac{1}{1-\alpha}\right)\right\}-\frac{H_{s}}{2}\left\{P t_{1}^{2}\right. \\
& \left.+\frac{1}{P_{s}}\left(-P^{2} t_{1}^{2} E\left(\frac{1}{1-\alpha}\right)-R^{2} E(1-\alpha)+2 R P t_{1}\right)\right\} \\
& -E(\alpha) H_{s}\left\{\frac{1}{2 P_{s}} E\left(\frac{P t_{1}}{1-\alpha}-R\right)^{2}+\frac{R^{2}}{R_{s}}\right. \\
& \left.\left.+\frac{P_{s}}{R_{s}}\left(P t_{1} E\left(\frac{1}{1-\alpha}\right)-R\right)\right\}-A_{s}-I_{s}\left(T-t_{1}\right)\right] \\
= & \frac{1}{T}\left[P t _ { 1 } \left\{W_{s}+S_{p} E\left(\frac{\alpha}{1-\alpha}\right)\right.\right. \\
& -\left(C_{s}+S_{s}\right) E\left(\frac{1}{1-\alpha}\right)-\frac{H_{s} R}{P_{s}} \\
& \left.-H_{s}\left(\frac{P_{s}}{R_{s}}-\frac{R}{P_{s}}\right) E(\alpha) E\left(\frac{1}{1-\alpha}\right)\right\}
\end{aligned}
$$




$$
\begin{aligned}
& +I_{s} t_{1}-\frac{H_{s}}{2} P t_{1}^{2}+P^{2} t_{1}^{2} \frac{H_{s}}{2 P_{s}}\left\{E\left(\frac{1}{1-\alpha}\right)\right. \\
& \left.-E(\alpha) E\left(\frac{1}{(1-\alpha)^{2}}\right)\right\}-\left\{A_{s}+I_{s} T\right. \\
& \left.\left.-\frac{H_{s} R^{2}}{2 P_{s}} E(1-2 \alpha)+\frac{H_{s} R}{R_{s}}\left(R-P_{s}\right) E(\alpha)\right\}\right] .
\end{aligned}
$$

From Eq. (20), the expected average profit of the manufacturer is:

$$
\begin{aligned}
& E A P_{M}=\frac{1}{T}\left[P t _ { 1 } \left\{W_{m}\left(1-E(\beta)+M_{p} E(\beta)\right)-S_{m}\right.\right. \\
& \left.-W_{s}-\delta_{m}\right\}-\left(A_{m}+I_{m} T\right)-H_{m} \frac{P^{2} t_{1}^{2}}{2 D_{r}} E(1-\beta)^{2} \\
& +H_{m}\left(\frac{1}{2}-E(\beta)\right) P t_{1}^{2}+\left(I_{m}-L\right) t_{1} \\
& \left.-\left(\gamma+\frac{E(\beta) H_{m}}{R_{m}}\right) P^{2} t_{1}\right] .
\end{aligned}
$$

From Eq. (28), the expected average profit of the retailer is:

$$
\begin{aligned}
E A P_{R}= & \frac{1}{T}\left[\left(W_{r}-W_{m}+\frac{H_{r}}{\theta}+d_{c}\right) D_{c} T-A_{r}\right. \\
& \left.-\left(\frac{H_{r}}{\theta}+d_{c}\right)(1-E(\beta)) P t_{1}\right] .
\end{aligned}
$$

Thus, the EIAP of the proposed three-layer supply chain is:

$$
E I A P=E A P_{S}+E A P_{M}+E A P_{R} .
$$

From Eqs. (29), (30), and (31), the EIAP of the supply chain is:

$$
\begin{aligned}
& E I A P=\frac{1}{T}\left[P t _ { 1 } \left\{S_{p} E\left(\frac{\alpha}{1-\alpha}\right)\right.\right. \\
& -\left(C_{s}+S_{s}\right) E\left(\frac{1}{1-\alpha}\right)-\frac{H_{s} R}{P_{s}} \\
& -H_{s}\left(\frac{P_{s}}{R_{s}}-\frac{R}{P_{s}}\right) E(\alpha) E\left(\frac{1}{1-\alpha}\right)-S_{m} \\
& -\delta_{m}+W_{m}\left(1-\left(1-M_{p}\right) E(\beta)\right) \\
& \left.-\left(\frac{H_{r}}{\theta}+d_{c}\right)(1-E(\beta))\right\}+\left\{H_{m}\left(\frac{1}{2}-E(\beta)\right)\right.
\end{aligned}
$$

$$
\begin{aligned}
& \left.-\frac{H_{s}}{2}\right\} P t_{1}^{2}-\left(\gamma+\frac{E(\beta) H_{m}}{R_{m}}\right) P^{2} t_{1} \\
& +P^{2} t_{1}^{2}\left\{\frac{H_{s}}{2 P_{s}}\left(E\left(\frac{\alpha}{1-\alpha}\right)-E(\alpha) E\left(\frac{1}{(1-\alpha)^{2}}\right)\right)\right. \\
& \left.-\frac{H_{m}}{2 D_{r}} E(1-\beta)^{2}\right\}+\left(I_{m}+I_{s}-L\right) t_{1} \\
& -\left(A_{r}+A_{s}+A_{m}\right)-\left(I_{s}+I_{m}\right) T \\
& +\frac{H_{s} R^{2}}{2 P_{s}} E(1-2 \alpha)-\frac{H_{s} R}{R_{s}}\left(R-P_{s}\right) E(\alpha) \\
& \left.+\left(W_{r}-W_{m}+\frac{H_{r}}{\theta}+d_{c}\right) D_{c} T\right] .
\end{aligned}
$$

The total expected average profit for the system of the three-layer SCM can be obtained from the above Eq. (32) for two variables $P$ and $t_{1}$.

\section{Optimization of proposed SCM}

The expected total profit EIAP of the three-layer SCM is also a function of two variables $P$ and $t_{1}$. Now, we have to calculate the optimality of two decision variables $P$ and $t_{1}$ and also for the optimum value of EIAP, the EIAP in Eq. (32) can be written as follows:

$$
\begin{aligned}
E I A P= & \frac{1}{T}\left[U_{1} P^{2} t_{1}^{2}-U_{2} P^{2} t_{1}+U_{3} P t_{1}^{2}+U_{4} P t_{1}\right. \\
& \left.+U_{5} t_{1}+U_{6}\right]
\end{aligned}
$$

where:

$$
\begin{aligned}
U_{1}= & \frac{H_{s}}{2 P_{s}}\left(E\left(\frac{\alpha}{1-\alpha}\right)-E(\alpha) E\left(\frac{1}{(1-\alpha)^{2}}\right)\right) \\
& -\frac{H_{m}}{2 D_{r}} E(1-\beta)^{2}, \\
U_{2}= & \gamma+\frac{E(\beta) H_{m}}{R_{m}}, \\
U_{3}= & H_{m}\left(\frac{1}{2}-E(\beta)\right)-\frac{H_{s}}{2}, \\
U_{4}= & S_{p} E\left(\frac{\alpha}{1-\alpha}\right)-\left(C_{s}+S_{s}\right) E\left(\frac{1}{1-\alpha}\right) \\
& -\frac{H_{s} R}{P_{s}-H_{s}\left(\frac{P_{s}}{R_{s}}-\frac{R}{P_{s}}\right) E(\alpha) E\left(\frac{1}{1-\alpha}\right)}
\end{aligned}
$$




$$
\begin{aligned}
& +W_{m}\left(1-\left(1-M_{p}\right) E(\beta)\right)-S_{m}-\delta_{m} \\
& -\left(\frac{H_{r}}{\theta}+d_{c}\right)(1-E(\beta)), \\
U_{5}= & I_{m}+I_{s}-L, \\
U_{6}= & -\left(I_{s}+I_{m}\right) T+\frac{H_{s} R^{2}}{2 P_{s}} E(1-2 \alpha) \\
& -\frac{H_{s}}{R} R_{s}\left(R-P_{s}\right) E(\alpha) \\
& +\left(W_{r}-W_{m}+\frac{H_{r}}{\theta}+d_{c}\right) D_{c} T \\
& -\left(A_{r}+A_{s}+A_{m}\right) .
\end{aligned}
$$

Proposition 1. To obtain the maximum average profit, there exists at least one positive point $\left(P^{*}, t_{1}^{*}\right)$ at which $\frac{\partial^{2} \mathrm{EIAP}}{\partial P^{2}}$ and $\frac{\partial^{2} \mathrm{EIAP}}{\partial t_{1}^{2}}$ both are negative, and Hessian Matrix $\left(\frac{\partial^{2} \mathrm{EIAP}}{\partial P^{2}} \quad \frac{\partial^{2} \mathrm{EIAP}}{\partial t_{1} \partial P} \frac{\partial^{2} \mathrm{EIAP}}{\partial P \partial t_{1}} \quad \frac{\partial^{2} \mathrm{EIAP}}{\partial t_{1}^{2}}\right)$ or $\frac{\partial^{2} \mathrm{EIAP}}{\partial P^{2}} \frac{\partial^{2} \mathrm{EIAP}}{\partial t_{1}^{2}}-\left(\frac{\partial^{2} \mathrm{EIAP}}{\partial P \partial t_{1}}\right)^{2}=\check{C} \check{D}-\check{E}^{2}$ must be positive where $\frac{\partial^{2} \mathrm{EIAP}}{\partial P^{2}}=\check{C}, \frac{\partial^{2} \mathrm{EIAP}}{\partial t_{1}^{2}}=\check{D}$ and $\frac{\partial^{2} \mathrm{EIAP}}{\partial P \partial t_{1}}=\check{E}$.

It is not possible to show the existence of the optimal solution analytically. For this reason, the conditions are assessed by a numerical example; however, the concavity is shown graphically. Figure 6 shows that the EIAP in Eq. (33) of the proposed three-layer SCM is followed by concavity property.

Lemma 4. The maximum EIAP exists if $\check{C}<0, \check{D}<$ 0 and $\breve{C} \breve{D}-\breve{E}^{2}>0$.

Proof. We know that for a stationary point $\left(x^{*}, y^{*}\right)$, a function $f(x, y)$ is called maximum if:

$$
\frac{\partial^{2} f\left(x^{*}, y^{*}\right)}{\partial x^{2}} \frac{\partial^{2} f\left(x^{*}, y^{*}\right)}{\partial y^{2}}-\left(\frac{\partial^{2} f\left(x^{*}, y^{*}\right)}{\partial x \partial y}\right)^{2}>0,
$$

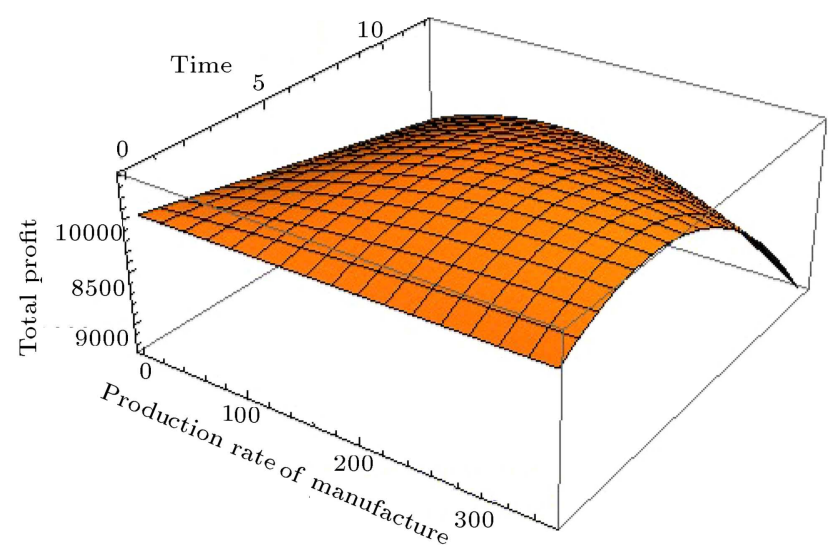

Figure 6. Graph of total profit vs production rate of manufacturer vs time. and:

$$
\frac{\partial^{2} f\left(x^{*}, y^{*}\right)}{\partial x^{2}}<0, \quad \frac{\partial^{2} f\left(x^{*}, y^{*}\right)}{\partial y^{2}}<0 .
$$

Now $\frac{\partial^{2} E I A P}{\partial P^{2}}=\check{C}>0$ as $\check{C}>0$ and $\frac{\partial^{2} E I A P}{\partial t_{1}^{2}}=$ $\check{D}>0$ as $\check{D}>0$ at $\left(P^{*}, t_{1}^{*}\right)$.

Also $\frac{\partial^{2} E I A P}{\partial P^{2}} \frac{\partial^{2} E I A P}{\partial t_{1}^{2}}-\left(\frac{\partial^{2} E I A P}{\partial P \partial t_{1}}\right)^{2}>0$ since $\check{C} \check{D}-$ $\check{E}^{2}>0$ where $\frac{\partial^{2} E I A P}{\partial P^{2}}=\check{C}, \frac{\partial^{2} E I A P}{\partial t_{1}^{2}}=\check{D}$ and $\frac{\partial^{2} E I A P}{\partial P \partial t_{1}}=$ $\check{E}$.

Therefore, all conditions of Proposition 1 are satisfied at point $\left(P^{*}, t_{1}^{*}\right)$. Hence, the maximum EIAP exists if $\check{C}<0, \check{D}<0$ and $\check{C} \check{D}-\check{E}^{2}>0$.

Lemma 5. If $\check{C}<0$ and $\check{D}>0$, then the maximum EIAP does not exist.

Proof. Here $\check{C}<0$ represents $\frac{\partial^{2} E I A P}{\partial P^{2}}<0$ at $\left(P^{*}, t_{1}^{*}\right)$ since $\frac{\partial^{2} E I A P}{\partial P^{2}}=\check{C}$, and $\check{D}>0$ represents $\frac{\partial^{2} E I A P}{\partial t_{1}^{2}}>0$ at $\left(P^{*}, t_{1}^{*}\right)$ since $\frac{\partial^{2} E I A P}{\partial t_{1}^{2}}=\check{D}$.

Therefore, one condition of Proposition 1 is not satisfied and so, there does not exist the maximum average profit.

Lemma 6. If $\check{C} \check{D}-\check{E}^{2}<0$, then the maximum EIAP does not exist.

Proof. Now, if $\check{C} \check{D}-\check{E}^{2}<0$, then $\frac{\partial^{2} E I A P}{\partial P^{2}} \frac{\partial^{2} E I A P}{\partial t_{1}^{2}}-$ $\left(\frac{\partial^{2} E I A P}{\partial P \partial t_{1}}\right)^{2}<0$, since $\frac{\partial^{2} E I A P}{\partial P^{2}}=\check{C}, \frac{\partial^{2} E I A P}{\partial t_{1}^{2}}=\check{D}$ and $\frac{\partial^{2} E I A P}{\partial P \partial t_{1}}=\check{E}$ at $\left(P^{*}, t_{1}^{*}\right)$.

Thus, all conditions of Proposition 1 are not satisfied at point $\left(P^{*}, t_{1}^{*}\right)$.

Therefore, if $\check{C} \check{D}-\check{E}^{2}<0$, then there does not exist the maximum EIAP at $\left(P^{*}, t_{1}^{*}\right)$.

The EIAP Eq. (33) of the three-layer SCM will give the optimal solution based on the following lemma. The conditions for the optimal total EIAP are analyzed.

Lemma 7. The condition of total EIAP is maximum as follows:

i) $H_{m} P_{s}\left\{2 D_{r} E(\beta)+R_{m} t_{1} E(1-\beta)^{2}\right\}$

$$
\begin{aligned}
& >R_{m} D_{r}\left[H _ { s } t _ { 1 } \left\{E\left(\frac{1}{1-\alpha}\right)\right.\right. \\
& \left.\left.-E(\alpha) E\left(\frac{1}{(1-\alpha)^{2}}\right)\right\}-2 \gamma P_{s}\right]
\end{aligned}
$$

ii) $H_{s} D_{r}\left[P\left\{E\left(\frac{1}{1-\alpha}\right)\right.\right.$ 


$$
\begin{aligned}
& \left.\left.-E(\alpha) E\left(\frac{1}{(1-\alpha)^{2}}\right)\right\}-P_{s}\right] \\
& <H_{m} P_{s}\left[P E(1-\beta)^{2}-2 D_{r}\left\{\frac{1}{2}-E(\beta)\right\}\right] .
\end{aligned}
$$

Proof. We have EIAP $=\frac{1}{T}\left[U_{1} P^{2} t_{1}^{2}-U_{2} P^{2} t_{1}+U_{3} P t_{1}^{2}+\right.$ $\left.U_{4} P t_{1}+U_{5} t_{1}+U_{6}\right]$ as:

$$
\begin{aligned}
& \frac{\partial E I A P}{\partial P}=\frac{1}{T}\left(2 U_{1} P t_{1}^{2}-2 U_{2} P t_{1}+U_{3} t_{1}^{2}+U_{4} t_{1}\right), \\
& \frac{\partial E I A P}{\partial t_{1}}=\frac{1}{T}\left(2 U_{1} P^{2} t_{1}-U_{2} P^{2}+2 U_{3} P t_{1}+U_{4} P+U_{5}\right)
\end{aligned}
$$$$
\frac{\partial^{2} E I A P}{\partial P^{2}}=\frac{2 t_{1}}{T}\left(U_{1} t_{1}-U_{2}\right)
$$$$
\frac{\partial^{2} E I A P}{\partial t_{1}^{2}}=\frac{2 P}{T}\left(U_{1} P+U_{3}\right),
$$$$
\frac{\partial^{2} E I A P}{\partial t_{1} \partial P}=\frac{1}{T}\left(4 U_{1} P t_{1}-2 U_{2} P+2 U_{3} t_{1}+U_{4}\right) .
$$

Based on the concept of optimality for several variables, from Eqs. (34) and (35), we get:

$$
\begin{aligned}
& 2 U_{1} P t_{1}-2 U_{2} P+U_{3} t_{1}+U_{4}=0, \\
& 2 U_{1} P^{2} t_{1}-U_{2} P^{2}+2 U_{3} P t_{1}+U_{4} P+U_{5}=0,
\end{aligned}
$$

and from Eqs. (36) and (37), we get:

$$
U_{1} t_{1}-U_{2}<0, \text { and } U_{1} P+U_{3}<0 \text {. }
$$

Thus, the necessary conditions are obtained as follows:

$$
\begin{aligned}
& H_{m} P_{s}\left\{2 D_{r} E(\beta)+R_{m} t_{1} E(1-\beta)^{2}\right\} \\
& >R_{m} D_{r}\left[H _ { s } t _ { 1 } \left\{E\left(\frac{1}{1-\alpha}\right)\right.\right. \\
& \left.\left.-E(\alpha) E\left(\frac{1}{(1-\alpha)^{2}}\right)\right\}-2 \gamma P_{s}\right], \\
& H_{s} D_{r}\left[P\left\{E\left(\frac{1}{1-\alpha}\right)-E(\alpha) E\left(\frac{1}{(1-\alpha)^{2}}\right)\right\}-P_{s}\right] \\
& <H_{m} P_{s}\left[P E(1-\beta)^{2}-2 D_{r}\left\{\frac{1}{2}-E(\beta)\right\}\right] .
\end{aligned}
$$

Therefore, the optimal solution of the proposed three-layer supply chain exists.

\section{Numerical example}

The theoretical demonstration of the proposed threelayer supply chain system is illustrated through a numerical example to study the feasibility. The values of the parameters of the model for numerical examples are not selected from any real-life case study; however, these values seem to be realistic. This model can be used in heavy industries like steel, chemicals, machinery, food, textile, etc.

We assume that the replenishment lot size of the raw material of the supplier is 300 units which also produces 400 units per unit time. The supplier purchases the raw material at the cost of $30 \$$ per unit item, and the holding cost of these raw materials is $3 \$$ per unit item. Let the cost associated with setting up a piece of production equipment for the supplier be $300 \$$ per unit item. Again, the screening rate of supplier is 1800 per unit time, and the cost of screening per unit item is $0.5 \$$. The selling price of the non-defective item is $54 \$$ per unit item and for the defective item is $10 \$$ per unit item. At the end of the supplier's inventory cycle, if it remains idle, then the costs for the supplier will be $200 \$$ per unit time.

The manufacturer purchases the raw material from the supplier for $54 \$$ per unit item, and the holding cost of these raw materials is $3 \$$ per unit item. The setup cost for the manufacturer is $400 \$$ per unit item, and the cost per unit finished product is $1 \$$. The total labor/energy costs per unit time of a production system are $1000 \$$, and the cost for tool per unit of the production rate is $0.02 \$$. The screening rate and the cost of screening by the manufacturer are $1750 \$$ per unit time and $0.5 \$$ per unit item, respectively. Again, the selling price of the non-defective item is $130 \$$ per unit item and for the defective item is $20 \%$ of the selling price of non-defective item per unit item. At the end of the supplier's inventory cycle, if it remains idle, then the costs for unit idle time is $150 \$$ per unit time.

The retailer purchases the finished product from the manufacturer at a cost of $130 \$$ per unit item, and the holding cost of these finished products is $5 \$$ per unit item. The retailer cost associated with the setting of infrastructure and maintaining of the inventory is $350 \$$ per unit item. Again, the selling price of the finished product is $140 \$$ per unit item. If the finished product is held for a longer time in the retailer warehouse, then the product will deteriorate with the rate of 0.08 per unit time and the cost of the deteriorated items is $8 \$$ per unit item. The demand rate of the retailer is 170 units per unit time and the demand rate of the customer is 130 units per unit time.

Numerical result and analysis of the above problem are solved using Mathematica and MATLAB software. For this model, we consider the data with the appropriate unit below: 
Table 1. Optimal solution of SCM for defective items for supplier and manufacturer.

\begin{tabular}{cccccc}
\hline $\boldsymbol{\alpha}$ & $\boldsymbol{\beta}$ & $\boldsymbol{P}^{*}$ & $\boldsymbol{t}_{\mathbf{1}}^{*}$ & $\boldsymbol{E I A P}^{*}(\$)$ & $\frac{\mathbf{1}}{b-\boldsymbol{a}}$ \\
\hline$(0.04,0.2)$ & $(0.05,0.2)$ & 298.846 & 5.126 & 10702.0 & $\frac{1}{0.16}$ \\
$(0.09,0.3)$ & $(0.1,0.3)$ & 261.994 & 3.132 & 10252.1 & $\frac{1}{0.21}$ \\
$(0.04,0.3)$ & $(0.05,0.3)$ & 276.577 & 3.808 & 10370.3 & $\frac{1}{0.26}$ \\
$(0.09,0.4)$ & $(0.1,0.4)$ & 218.928 & 1.472 & 10082.4 & $\frac{1}{0.31}$ \\
\hline
\end{tabular}

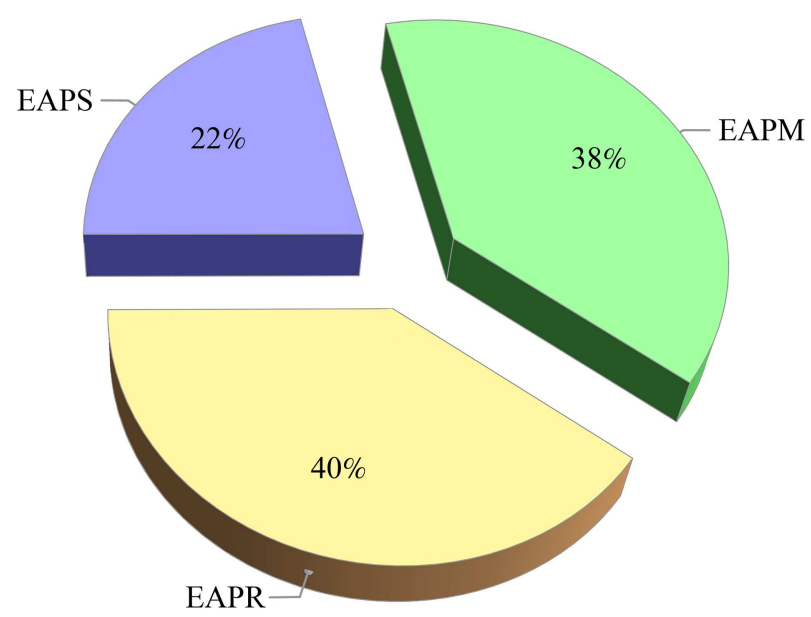

Figure 7. Percentage of optimal cost at the individual level.

$$
\begin{array}{lll}
R=300, & A_{s}=300, & H_{s}=3, \\
W_{s}=54, & S_{p}=10, & P_{s}=400, \\
R_{s}=1800, & S_{s}=0.5, & I_{s}=200, \\
C_{s}=30, & I_{m}=150, & H_{m}=2, \\
S_{m}=0.5, & R_{m}=1750, & W_{m}=130, \\
M_{p}=0.2, & A_{m}=400, & \delta_{m}=1, \\
\theta=0.08, & L=1000, & \gamma=0.02, \\
A_{r}=350, & W_{r}=140, & H_{r}=5, \\
D_{r}=170, & D_{c}=130, & d_{c}=8, \quad T=12 .
\end{array}
$$

From Table 1, the optimal value of $t_{1}$ is $t_{1}^{*}=5.126$; the optimum production rate is $P^{*}=298.846$; and the optimum total EIAP EIAP* for the three-layer SCM is $10702 \$$.

Figure 7 shows the percentage of optimal cost at the individual level of the three-layer SCM, where we observe that the total cost of retailer is the maximum share of the total cost. In Figure 8, we also compare the individual costs of supplier, manufacturer, and retailer, along with the optimum total EIAP.

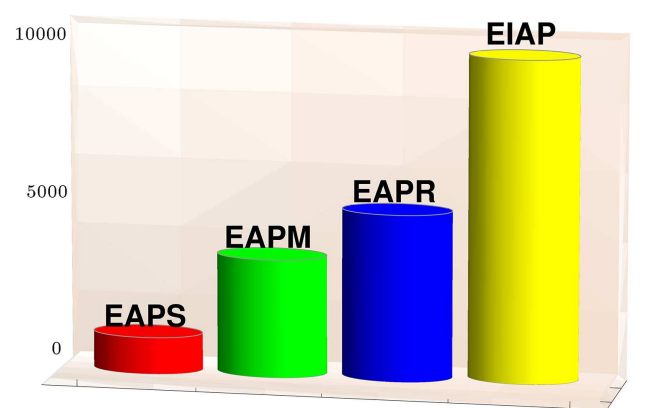

Figure 8. Comparison between total cost and individual cost.

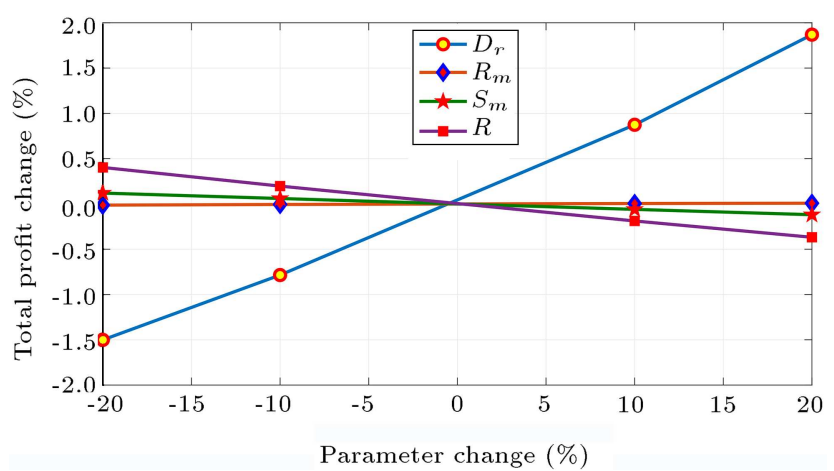

Figure 9. Percentage change of total profit vs change of parameter.

\section{Sensitivity analysis and managerial implications}

Here, the aim is to discuss the effect of the changes in different parameters in different percentage changes for analyzing the proposed three-layer SCM. Sensitivity analysis is performed by increasing and decreasing the values of the parameters considering the changes in one parameter at a time for analysis, and the other parameter remains unchanged.

Table 2 and Figures 9, 10, and 11 show the following nature of the proposed three-layer SCM. The model is highly sensitive to the demand rate of customer $\left(D_{c}\right)$. As the demand rate of customer increases, the total profit of the system increases, and vice versa. The total profit of the SCM rises with the demand of retailer $\left(D_{r}\right)$, whose managerial significance leads to the production of more items 
Table 2. Sensitivity analysis of the proposed model for rate parameters.

\begin{tabular}{|c|c|c|c|c|c|c|c|}
\hline Parameter & Change (\%) & $P$ & $t_{s}$ & $t_{1}$ & $t_{2}$ & $E I A P(\$)$ & Change $E I A P(\%)$ \\
\hline \multirow{4}{*}{$D_{c}$} & -20 & 298.846 & 3.614 & 5.126 & 7.885 & 8609.0 & -19.557 \\
\hline & -10 & 298.846 & 3.614 & 5.126 & 7.885 & 9655.5 & -9.779 \\
\hline & 10 & 298.846 & 3.614 & 5.126 & 7.885 & 11748.5 & 9.779 \\
\hline & 20 & 298.846 & 3.614 & 5.126 & 7.885 & 12795.0 & 19.557 \\
\hline \multirow{4}{*}{$D_{r}$} & -20 & 271.941 & 2.438 & 4.116 & 7.201 & 10541.4 & -1.501 \\
\hline & -10 & 284.840 & 2.988 & 4.607 & 7.505 & 10618.0 & -0.785 \\
\hline & 10 & 314.354 & 4.342 & 5.686 & 8.364 & 10795.5 & 0.874 \\
\hline & 20 & 332.006 & 5.214 & 6.306 & 8.980 & 10902.0 & 1.869 \\
\hline \multirow{4}{*}{$R_{m}$} & -20 & 298.432 & 3.607 & 5.125 & 7.872 & 10700.6 & -0.013 \\
\hline & -10 & 298.662 & 3.611 & 5.126 & 7.880 & 10701.4 & -0.006 \\
\hline & 10 & 298.997 & 3.616 & 5.126 & 7.889 & 10702.5 & 0.005 \\
\hline & 20 & 299.122 & 3.619 & 5.127 & 7.894 & 10702.9 & 0.008 \\
\hline \multirow{4}{*}{$R_{s}$} & -20 & 298.604 & 3.603 & 5.117 & 7.864 & 10699.2 & -0.026 \\
\hline & -10 & 298.738 & 3.609 & 5.122 & 7.876 & 10700.8 & -0.012 \\
\hline & 10 & 298.934 & 3.618 & 5.129 & 7.892 & 10703.0 & 0.009 \\
\hline & 20 & 299.007 & 3.621 & 5.132 & 7.898 & 10703.9 & 0.017 \\
\hline \multirow{4}{*}{$P_{s}$} & -10 & 311.773 & 4.686 & 5.594 & 8.975 & 10767.1 & 0.608 \\
\hline & -5 & 304.486 & 4.078 & 5.331 & 8.355 & 10730.4 & 0.265 \\
\hline & 5 & 294.336 & 3.247 & 4.961 & 7.516 & 10679.3 & -0.212 \\
\hline & 10 & 290.638 & 2.949 & 4.824 & 7.216 & 10660.7 & -0.385 \\
\hline \multirow{4}{*}{$R$} & -20 & 302.963 & 3.954 & 5.276 & 8.227 & 10745.1 & 0.403 \\
\hline & -10 & 300.905 & 3.783 & 5.201 & 8.055 & 10723.1 & 0.197 \\
\hline & 10 & 296.785 & 3.445 & 5.051 & 7.716 & 10681.8 & -0.188 \\
\hline & 20 & 294.722 & 3.277 & 4.975 & 7.547 & 10662.6 & -0.368 \\
\hline
\end{tabular}

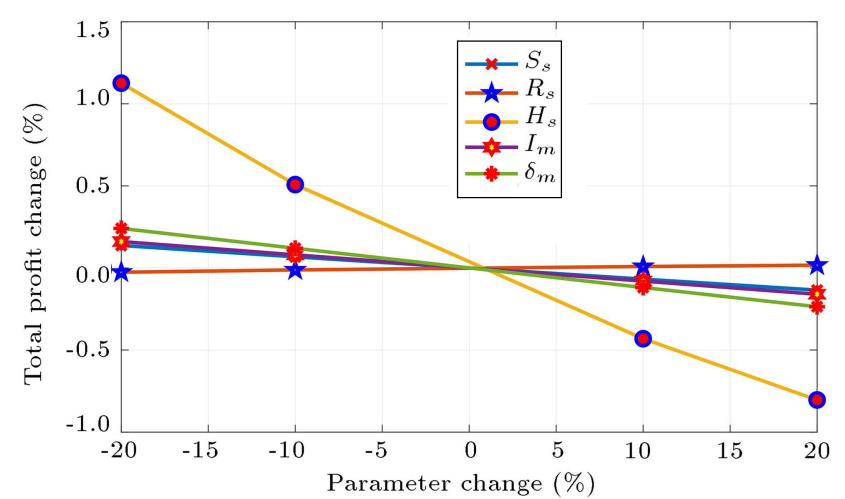

Figure 10. Percentage change of total profit vs change of parameter.

by the manufacturer, hence increased sales to the customer and higher system profit. The proposed SCM responded to the screening rate of supplier $\left(R_{s}\right)$ and screening rate of manufacturer $\left(R_{m}\right)$. Therefore, a proper managerial decision can be taken from this study of the SCM to increase the profit of the supply chain system. The optimal total cost is very less

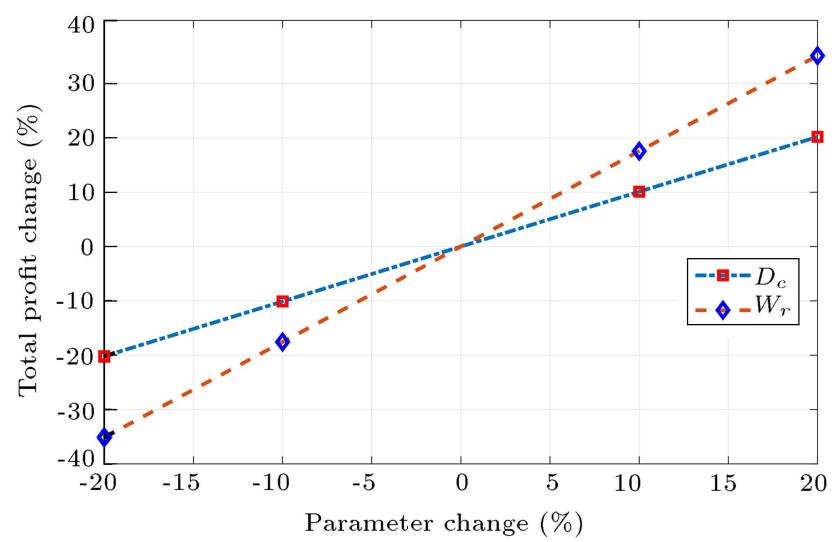

Figure 11. Percentage change of total profit vs change of parameter $D_{c}, W_{c}$.

sensitive to the initial stock level of the supplier $(R)$ in reverse proportion, because the initial stock level increases imply that the supplier produces less items and also, the profit decreases for the supply chain system. The proposed SCM interacts slowly with the production rate of supplier $\left(P_{s}\right)$ in reverse proportion, 
because the increase in $\left(P_{s}\right)$ implies that more items will be produced in a short time and the supplier's total profit will decrease, as well.

This study reflects the quality concept of the products for both the supplier and manufacturer due to screening implementation. This study developed an SCM of the production model to convert the raw materials into a finished product to satisfy the demand of customers in time, which is a common phenomenon of managerial insights. We have considered the idle costs of supplier and manufacturer to date, which will help reduce the idle time of machines.

On the basis of sensitivity analysis presented in Figures 9-13 and Table 3, the following observations are made for different cost parameters of the threelayer SCM. The model is highly sensitive to the selling price of retailer $\left(W_{r}\right)$. If we increase $\left(W_{r}\right)$, the profit of the retailer automatically increases and thus, the total profit increases. It is also seen that the decision variables $P$ and $t_{1}$ are constant because the variables are independent of $\left(W_{r}\right)$. The model is sensitive to the screening cost of supplier $\left(S_{s}\right)$ and manufacturer $\left(S_{m}\right)$ in reverse proportion.

The expected total profit is moderately sensitive to the purchasing cost of supplier $\left(C_{s}\right)$ in reverse

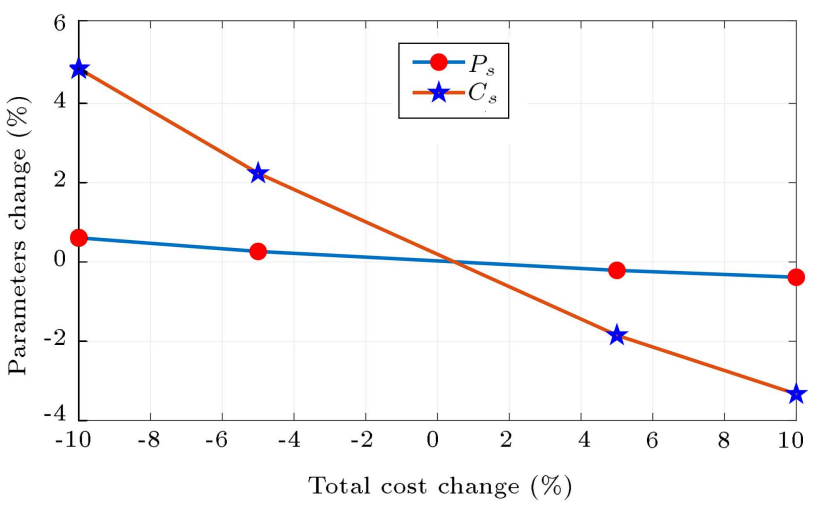

Figure 12. Percentage change of total profit vs change of parameter.

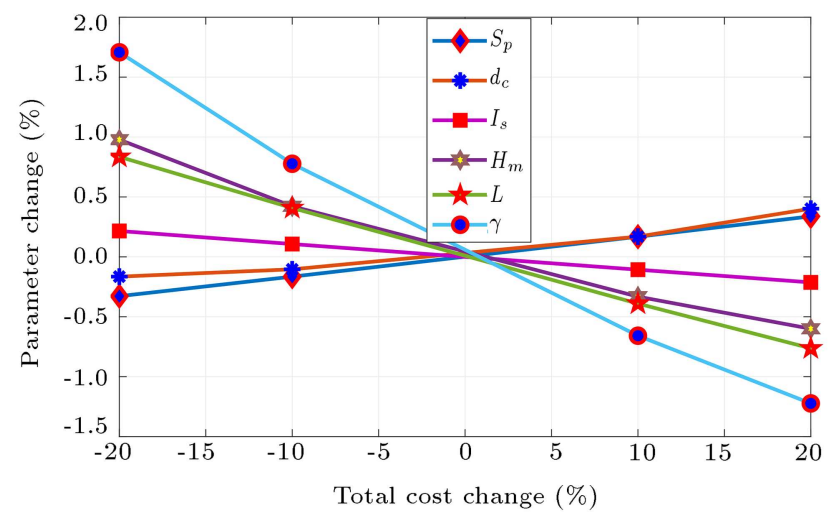

Figure 13. Percentage change of total profit vs change of parameter. proportion. The managerial impact of this change of supplier is real because an increase in purchasing cost restricts supplier in buying items. Accordingly, fewer items are sold to the manufacturer. Hence, the total profit of the proposed supply chain system decreases as an impact of fewer items produced by the manufacturer. The supply chain management would take a decision about the selling price of defective items of supplier $\left(S_{p}\right)$ to increase the profit of supplier; hence, the total profit of the SCM increases. This paper shows that the profit is reduced at a higher screening cost at the level of supplier and manufacturer. The cost due to idle time of supplier $\left(I_{s}\right)$ and manufacturer $\left(I_{m}\right)$ has an impact on the optimal expected total profit of the model. Costs for idle time increase mean the purchase cost increases and hence, the total profit of the system decreases. The model is sensitive to the cost of the deteriorating item $\left(d_{c}\right)$, because the managerial decision would help the retailer to gain profit from deteriorating items at higher costs after discount. However, the cost of a deteriorating item should be decided to concentrate on the cost of nondefective items.

Based on the sensitivity analysis, shown in Table 4 and Figures 10 and 13, few observations have been made. The total profit of supplier decreases due to increase in the average of the holding cost $\left(H_{s}\right)$. It is also seen that as the holding cost of supplier increases, the demand rate of supplier $P$ increases; thus, more items are sold to the manufacturer. Also, the time $t_{1}$ decreases, which means that the supplier must hold the products for a shorter span of time, leading to the reduction of the total profit of the model. The supply chain system shows that if the holding cost at the manufacturer $\left(H_{m}\right)$ level increases, then the total profit of the manufacturer is reduced. It was also observed from this proposed model that if the holding cost increased, then the production rate for the supplier decreased; thus, less quantity of items would be produced by the manufacturer. The rise of labor/energy costs $(L)$ implies that the total profit decreases, and vice versa. The total profit of this model decreases due to increase in tool cost $(\gamma)$ and cost per unit finished product $\left(\delta_{m}\right)$ due to the increase in $(\gamma)$ and $\left(\delta_{m}\right)$. This supply chain system shows that as the tool cost and cost per item of the finished product increase, the demand rate of the supplier and the time $t_{1}$ are reduced, meaning that the manufacturer produces items in less quantity in a shorter span of time. Therefore, the manufacturer's profit as well as the total profit of SCM are reduced.

\section{Conclusion and future research}

Several researchers have discussed integrated vendorbuyer inventory models and the joint optimization 
Table 3. Sensitivity analysis of the proposed model for cost parameters.

\begin{tabular}{|c|c|c|c|c|c|c|c|}
\hline Parameter & Change (\%) & $\boldsymbol{P}$ & $t_{s}$ & $t_{1}$ & $t_{2}$ & $E I A P(\$)$ & Change EIAP (\%) \\
\hline \multirow{4}{*}{$W_{r}$} & -20 & 298.846 & 3.614 & 5.126 & 7.885 & 7062.0 & -34.012 \\
\hline & -10 & 298.846 & 3.614 & 5.126 & 7.885 & 8882.0 & -17.006 \\
\hline & 10 & 298.846 & 3.614 & 5.126 & 7.885 & 12522.0 & 17.006 \\
\hline & 20 & 298.846 & 3.614 & 5.126 & 7.885 & 14342.0 & 34.012 \\
\hline \multirow{4}{*}{$S_{p}$} & -20 & 295.884 & 3.480 & 5.018 & 7.642 & 10666.9 & -0.328 \\
\hline & -10 & 297.366 & 3.547 & 5.072 & 7.763 & 10684.3 & -0.165 \\
\hline & 10 & 300.325 & 3.682 & 5.180 & 8.007 & 10719.9 & 0.168 \\
\hline & 20 & 301.804 & 3.750 & 5.234 & 8.131 & 10738.2 & 0.338 \\
\hline \multirow{4}{*}{$S_{m}$} & -20 & 299.906 & 3.663 & 5.165 & 7.973 & 10714.8 & 0.120 \\
\hline & -10 & 299.376 & 3.638 & 5.145 & 7.928 & 10708.4 & 0.060 \\
\hline & 10 & 298.315 & 3.590 & 5.107 & 7.842 & 10695.6 & -0.060 \\
\hline & 20 & 297.785 & 3.565 & 5.087 & 7.797 & 10689.3 & -0.119 \\
\hline \multirow{4}{*}{$S_{s}$} & -20 & 300.054 & 3.669 & 5.170 & 7.985 & 10716.6 & 0.137 \\
\hline & -10 & 299.450 & 3.642 & 5.148 & 7.935 & 10709.3 & 0.068 \\
\hline & 10 & 298.241 & 3.586 & 5.104 & 7.835 & 10694.7 & -0.068 \\
\hline & 20 & 297.637 & 3.559 & 5.082 & 7.785 & 10687.5 & -0.135 \\
\hline \multirow{4}{*}{$I_{m}$} & -20 & 300.606 & 3.581 & 5.057 & 7.824 & 10719.3 & 0.161 \\
\hline & -10 & 299.728 & 3.598 & 5.092 & 7.856 & 10710.6 & 0.080 \\
\hline & 10 & 297.961 & 3.631 & 5.161 & 7.915 & 10693.4 & -0.080 \\
\hline & 20 & 397.072 & 3.647 & 5.196 & 7.945 & 10684.9 & -0.160 \\
\hline \multirow{4}{*}{$I_{s}$} & -20 & 301.190 & 3.570 & 5.035 & 7.805 & 10725.1 & 0.216 \\
\hline & -10 & 300.021 & 3.592 & 5.080 & 7.845 & 10713.5 & 0.107 \\
\hline & 10 & 297.665 & 3.636 & 5.172 & 7.924 & 10690.6 & -0.107 \\
\hline & 20 & 296.477 & 3.658 & 5.219 & 7.964 & 10679.2 & -0.213 \\
\hline \multirow{4}{*}{$C_{s}$} & -10 & 334.797 & 5.357 & 6.403 & 11.034 & 11224.2 & 4.879 \\
\hline & -5 & 316.903 & 4.464 & 5.776 & 9.421 & 10941.3 & 2.236 \\
\hline & 5 & 280.650 & 2.807 & 4.449 & 6.427 & 10504.2 & -1.849 \\
\hline & 10 & 262.348 & 2.047 & 3.742 & 5.053 & 10345.5 & -3.331 \\
\hline \multirow{4}{*}{$d_{c}$} & -20 & 313.647 & 4.037 & 5.357 & 8.648 & 10684.4 & -0.165 \\
\hline & -10 & 306.259 & 3.957 & 5.395 & 8.504 & 10690.9 & -0.104 \\
\hline & 10 & 291.409 & 3.278 & 4.852 & 7.278 & 10720.1 & 0.169 \\
\hline & 20 & 283.951 & 2.950 & 4.574 & 6.685 & 10745.0 & 0.402 \\
\hline
\end{tabular}

of inventory policies to maximize total profit for the supply chain. This study developed a three-layer supply chain system for a production inventory model consisting of supplier, manufacturer, and retailer as the members of the chain. The idle cost of supplier and manufacturer as well as the constant demand rate of the supplier, manufacturer, and retailer were considered. The defective items at suppliers and manufacturers were assumed with the proportion factors of defective items that follow a uniform distribution function. It was also assumed that the screening rate was less than or equal to the production rate as well as greater than the demand rate. The deterioration was allowed to produce items at the retailer end.

This paper expanded, upgraded, and complemented many existing articles. The major contribution is finite replenishment with supplier production rates, idle times, and the effect of imperfect items on the proposed supply chain model compared to the existing literature. In the numerical example, the optimal total cost and the optimal value of two decision variables $P$ (production rate of the manufacturer) and $t_{1}$ (Halting 
Table 4. Sensitivity analysis of the proposed SCM for other inventory parameters.

\begin{tabular}{|c|c|c|c|c|c|c|c|}
\hline Parameter & Change (\%) & $\boldsymbol{P}$ & $t_{s}$ & $t_{1}$ & $t_{2}$ & $\operatorname{EIAP}(\$)$ & Change EIAP (\%) \\
\hline \multirow{4}{*}{$H_{s}$} & -20 & 264.635 & 4.065 & 6.387 & 8.700 & 10822.5 & 1.126 \\
\hline & -10 & 282.800 & 3.812 & 5.663 & 8.243 & 10756.4 & 0.508 \\
\hline & 10 & 313.364 & 3.454 & 4.709 & 7.595 & 10655.9 & -0.431 \\
\hline & 20 & 326.739 & 3.320 & 4.373 & 7.354 & 10615.9 & -0.804 \\
\hline \multirow{4}{*}{$H_{m}$} & -20 & 341.495 & 4.617 & 5.517 & 9.697 & 10806.7 & 0.978 \\
\hline & -10 & 317.968 & 4.033 & 5.280 & 8.641 & 10747.1 & 0.422 \\
\hline & 10 & 282.535 & 3.298 & 5.029 & 7.313 & 10666.5 & -0.332 \\
\hline & 20 & 268.145 & 3.050 & 4.975 & 6.866 & 10637.8 & -0.600 \\
\hline \multirow{4}{*}{$\delta_{m}$} & -20 & 300.966 & 3.712 & 5.204 & 8.061 & 10727.8 & 0.241 \\
\hline & -10 & 299.906 & 3.663 & 5.165 & 7.973 & 10714.8 & 0.120 \\
\hline & 10 & 297.785 & 3.565 & 5.087 & 7.797 & 10689.3 & -0.119 \\
\hline & 20 & 296.723 & 3.517 & 5.048 & 7.710 & 10676.7 & -0.236 \\
\hline \multirow{4}{*}{$L$} & -20 & 286.736 & 3.831 & 5.608 & 8.277 & 10791.4 & 0.835 \\
\hline & -10 & 292.876 & 3.724 & 5.362 & 8.083 & 10745.7 & 0.408 \\
\hline & 10 & 304.661 & 3.503 & 4.900 & 7.684 & 10660.2 & -0.390 \\
\hline & 20 & 310.334 & 3.389 & 4.682 & 7.479 & 10620.3 & -0.763 \\
\hline \multirow{4}{*}{$\gamma$} & -20 & 355.039 & 4.510 & 5.201 & 9.504 & 10884.7 & 1.707 \\
\hline & -10 & 324.254 & 4.027 & 5.171 & 8.630 & 10785.2 & 0.777 \\
\hline & 10 & 277.492 & 3.257 & 5.069 & 7.240 & 10631.5 & -0.658 \\
\hline & 20 & 259.276 & 2.946 & 5.004 & 6.678 & 10571.1 & -1.223 \\
\hline
\end{tabular}

of production by manufacturers) were evaluated by incorporating all the expenses of the three layers. A numerical example with sensitivity analysis was given to study the feasibility of the proposed model with respect to the effect of changes in the various parameters involved in this study. From the sensitivity analysis, it was found that the model was highly sensitive to the change in demand rate of the customer and selling price of the retailer, and it was less sensitive to the change in the purchasing cost of the supplier. This study determined that not only could the production rate of supplier and manufacturer be a decisive factor in optimizing the total profit of the inventory, but also the selling price of the retailer, demand rate of the customer, purchasing cost of supplier, and holding cost were instrumental in expanding the profit of the business in real terms. This paper established the coordination among production, demand rate, and selling price across the supply chain models for the optimum integrated average profit of the supply chain.

This study can be extended considering the machine breakdown and repairing costs of corrective and preventive maintenance for the manufacturer. The model can be studied in stock-out situations in each stage of the chain given the uncertainties involved in the delivery, production, and demand of customers. Interested researchers can extend this work by considering the effect of inspection error and reworking by the manufacturer. This model can further be extended by considering the following aspects: defective items of supplier and manufacturer, the production rate of supplier and manufacturer being time and reliability dependent, probabilistic demand rate of the retailer, variable deterioration rate, deterioration in each stage, shortages with full or partial backlogging in every stage, quantity discounts, multiple suppliers, multiple manufacturers, etc. These are some crucial outlines for further topics of future research on the supply chain system.

\section{Acknowledgement}

We are grateful to Editor-in-Chief, Editor, and anonymous referees for their valuable comments and helpful suggestions, which have helped improve this work significantly. 


\section{References}

1. Hsu, J.T. and Hsu, L.F. "An integrated single-vendor single-buyer production inventory model for items with imperfect quality and inspection errors", International Journal of Industrial Engineering Computations, 3, pp. 703-720 (2012).

2. Bottani, E. and Montanari, R. "Supply chain design and cost analysis through simulation", International Journal of Production Research, 48, pp. 2859-2886 (2010).

3. Costantino, N., Dotoli, M., Falagario, M., et al. "A model for supply management of agile manufacturing supply chains", International Journal of Production Economics, 135, pp. 451-457 (2012).

4. Dominguez, R., Cannella, S., and Framinan, J.M. "The impact of the supply chain structure on bullwhip effect", Applied Mathematical Modelling, 39, pp. 73097325 (2014).

5. Trevino-Garza, G., Castillo-Villar, K.K., and Cardenas-Barron, L.E. "Joint determination of the lot size and number of shipments for a family of integrated vendor-buyer systems considering defective products", International Journal of Systems Science, 46, pp. 1705-1716 (2015).

6. Beck, F., Glock, C.H., and Kim, T. "Coordination of a production network with a single buyer and multiple vendors with unequal-sized batch shipments", International Journal of Production Economics, 193, pp. 633-646 (2017).

7. Li, T., Zhao, X., and Xie, J. "Inventory management for dual sales channels with inventory-level-dependent demand", Journal of the Operational Research Society, 66, pp. 488-499 (2015).

8. Chung, K.J., Liao, J.J., Ting, P.S., et al. "The algorithm for the optimal cycle time and pricing decisions for an integrated inventory system with order-size dependent trade credit in supply chain management", Applied Mathematics and Computation, 268, pp. 322333 (2015).

9. Li, J., Wang, S., and Cheng, T.C.E. "Competition and cooperation in a single retailer two-supplier supply chain with supply disruption", International Journal of Production Economics, 124, pp. 137-150 (2010).

10. AlDurgam, M., Adegbola, K., and Glock, C.H. "A single-vendor single-manufacturer integrated inventory model with stochastic demand and variable production rate", International Journal of Production Economics, 191, pp. 335-350 (2017).

11. Pasandideh, S.H.R., Niaki, S.T.A., and Ahmadi, P. "Vendor-managed inventory in the joint replenishment problem of a multi-product single-supplier multipleretailer supply chain: a teacher-learner-based optimization algorithm", Journal of Modeling in Management, 13, pp. 156-178 (2018).

12. Ghiami, Y. and Williams, T. "A two-echelon production-inventory model for deteriorating items with multiple buyers", International Journal of Production Economics, 159, pp. 233-240 (2015).

13. Li, J., Wang, S., and Cheng, T.C.E. "Competition and cooperation in a single-retailer two-supplier supply chain with supply disruption", International Journal of Production Economics, 124, pp. 137-150 (2010).

14. Ben-Daya, M., Hassini, E., Hariga, M., et al. "Consignment and vendor managed inventory in single-vendor multiple buyers supply chains", International Journal of Production Research, 51, pp. 1347-1365 (2013).

15. Glock, C.H. and Kim, T. "Container management in a single-vendor-multiple-buyer supply chain", Logistics Research, 7, p. 112 (2014).

16. Um, J., Lyons, A., Lam, H.K.S., et al. "Product variety management and supply chain performance: A capability perspective on their relationships and competitiveness implications", International Journal of Production Economics, 187, pp. 15-26 (2017).

17. Gharaei, A., Pasandideh, S.H.R., and Niaki, S.T.A. "An optimal integrated lot sizing policy of inventory in a bi-objective multi-level supply chain with stochastic constraints and imperfect products", Journal of Industrial and Production Engineering, 35, pp. 6-20 (2018).

18. Pavlov, A., Ivanov, D., Dolgui, A., et al. "Hybrid fuzzy-probabilistic approach to supply chain resilience assessment", IEEE Transactions on Engineering Management, 65, pp. 303-315 (2018).

19. Govindan, K. and Cheng, T.C.E. "Advances in stochastic programming and robust optimization for supply chain planning", Computers and Operations Research, 100, pp. 262-269 (2018).

20. Dolgui, A., Tiwari, M.K., Sinjana, Y., et al. "Optimising integrated inventory policy for perishable items in a multi-stage supply chain", International Journal of Production Research, 56, pp. 902-925 (2018).

21. Kerkkamp, R.B.O., Heuvel, W.V.D., and Wagelmans, A.P.M. "Two-echelon supply chain coordination under information asymmetry with multiple types", Omega, 76, pp. 137-159 (2018).

22. Abbasi, B., Mirzazadeh, A., and Mohammadi, M. "Multi stage investment planning and customer selection in a two echelon multi-period supply chain", Scientia Iranica, 26, pp. 3032-3050 (2019).

23. Mohammadi, A.S., Alemtabriz, A., Pishvaee, M.S., et al. "A multi-stage stochastic programming model for sustainable closed-loop supply chain network design with financial decisions: A case study of plastic production and recycling supply chain", Scientia Iranica, 27, pp. 377-395 (2020).

24. Inderfurth, K., Kelle, P., and Kleber, R. "Inventory control in dual sourcing commodity procurement with price correlation", Central European Journal of Operations Research, 26, pp. 93-119 (2018).

25. Jonkman, J., Barbosa-Póvoa, A.P., and Bloemhof, J.M. "Integrating harvesting decisions in the design of agro-food supply chains", European Journal of Operational Research, 276, pp. 247-258 (2019). 
26. Ben-Daya, M. and Seliaman, M. "An integrated production inventory model with raw material replenishment considerations in a three-layer supply chain", International Journal of Production Economics, 28, pp. 11-21 (2010).

27. Besheli, S.F., Keshteli, R.N., Emami, S., et al. "A fuzzy dynamic multi-objective, multi-item model by considering customer satisfaction in supply chain", Scientia Iranica, 24, pp. 2623-2639 (2017).

28. Hajikhani, A., Khalilzadeh, M., and Sadjadi, S.J. "A fuzzy multi-objective multi-product supplier selection and order allocation problem in supply chain under coverage and price considerations: An urban agricultural case study", Scientia Iranica, 25, pp. 431-449 (2018).

29. Taleizadeh, A.A. and Noori-daryan, M. "Pricing, manufacturing and inventory policies for raw material in a three-levelsupply chain", International Journal of Systems Science, 47, pp. 919-931 (2014).

30. Gamasaee, R. and Fazel Zarandi, M.H. "Incorporating demand, orders, lead time, and pricing decisions for reducing bullwhip effect in supply chains", Scientia Iranica, 25, pp. 1724-1749 (2018).

31. Taleizadeh, A.A., Haghighi, F., and Niaki, S.T.A. "Modeling and solving a sustainable closed loop supply chain problem with pricing decisions and discounts on returned products", Journal of Cleaner Production, 207, pp. 163-181 (2019).

32. Hsu, J.T. and Hsu, L.F. "An integrated vendor buyer cooperative inventory model in an imperfect production process with shortage backordering", The International Journal of Advanced Manufacturing Technology, 65, pp. 493-505 (2013).

33. Khan, M., Jaber, M.Y., and Bonney, M. "An economic order quantity (EOQ) for items with imperfect quality and inspection errors", International Journal of Production Economics, 133, pp. 113-118 (2011).

34. Salameh, M.K. and Jaber, M.Y. "Economic production quantity model for items with imperfect quality", International Journal of Production Economics, 64, pp. 59-64 (2010).

35. Kim, T. and Glock, C.H. "A multi-stage joint economic lot size model with lead time penalty costs", Computers \& Industrial Engineering, 66, pp. 133-146 (2013).

36. Pal, S., Mahapatra, G.S., and Samanta, G.P. “An EPQ model of ramp type demand with Weibull deterioration under inflation and finite horizon in crisp and fuzzy environment", International Journal of Production Economics, 156, pp. 159-166 (2014).

37. Jaggi, C.K., Cárdenas-Barrón, L.E., Tiwari, S., et al. "Two-warehouse inventory model for deteriorating items with imperfect quality under the conditions of permissible delay in payments", Scientia Iranica, 24, pp. 390-412 (2017).

38. Taleizadeh, A.A., Noori-daryan, M., and TavakkoliMoghaddam, R. "Pricing and ordering decisions in a supply chain with imperfect quality items and inspection under a buyback contract", International Journal of Production Research, 53, pp. 4553-4582 (2015).

39. Pal, S., Mahapatra, G.S., and Samanta, G.P. "A production inventory model for deteriorating item with ramp type demand allowing inflation and shortages under fuzziness", Economic Modelling, 46, pp. 334345 (2015).

40. Ivanov, D., Dolgui, A., and Sokolov, B. "Scheduling of recovery actions in the supply chain with resilience analysis considerations", International Journal of Production Research, 56, pp. 6473-6490 (2018).

41. Cannella, S., Dominguez, R., Ponte, B., et al. "Capacity restrictions and supply chain performance: Modelling and analysing load-dependent lead times", International Journal of Production Economics, 204, pp. 264-277 (2018).

42. Mahapatra, G.S., Adak, S., and Kaladhar, K. "A fuzzy inventory model with three-parameter Weibull deterioration with reliant holding cost and demand incorporating reliability", Journal of Intelligent \& Fuzzy Systems, 36, pp. 5731-5744 (2019).

43. Taleizadeh, A.A., Akhavizadegan, F., and Ansarifar, J. "Pricing and quality level decisions of substitutable products in online and traditional selling channels: game-theoretical approaches", International Transactions in Operational Research, 26, pp. 1718-1751 (2019).

44. Shaikh, A.A., Khan, M.A.A., Panda, G.C., et al. "Price discount facility in an EOQ model for deteriorating items with stock-dependent demand and partial backlogging", International Transactions in Operational Research, 26, pp. 1365-1395 (2019).

45. Pal, S., Mahapatra, G.S., and Samanta, G.P. "A threelayer supply chain EPQ model for price-and stockdependent stochastic demand with imperfect item under rework", Journal of Uncertainty Analysis and Applications, 4, p. 10 (2016).

46. Pal, B., Sana, S.S., and Chaudhuri, K. "Three-layer supply chain - A production inventory model for reworkable items", Applied Mathematics and Computation, 219, pp. 530-543 (2012).

47. Jian, L., Zhen, W., Bao, J., et al. "Coordination strategies in a three-echelon reverse supply chain for economic and social benefit", Applied Mathematical Modeling, 49, pp. 599-611 (2017).

48. Pal, S. and Mahapatra, G.S. "A manufacturingoriented supply chain model for imperfect quality with inspection errors, stochastic demand under rework and shortages", Computers \& Industrial Engineering, 106, pp. 299-314 (2017).

49. Khan, M., Jaber, M.Y., and Ahmad, A.R. "An integrated supply chain model with errors in quality inspection and learning in production", Omega, 42, pp. 16-24 (2014).

50. Feng, L., Chan, Y.L., and Cardenas-Barron, L.E. "Pricing and lot-sizing polices for perishable goods 
when the demand depends on selling price, displayed stocks, and expiration date", International Journal of Production Economics, 185, pp. 11-20 (2017).

51. Dye, C.Y. "A finite horizon deteriorating inventory model with two-phase pricing and time-varying demand and cost under trade credit financing using particle swarm optimization", Swarm and Evolutionary Computation, 5, pp. 37-53 (2012).

52. Chung, K.J. and Cárdenas-Barrón, L.E. "The simplified solution procedure for deteriorating items under stock-dependent demand and two-level trade credit in the supply chain management", Applied Mathematical Modelling, 37, pp. 4653-4660 (2013).

53. Gao, D., Zhao, X., and Geng, W. "A delay-in-payment contract for Pareto improvement of a supply chain with stochastic demand", Omega, 49, pp. 60-68 (2014).

54. Chan, C.K., Wong, W.H., Langevin, A., et al. "An integrated production-inventory model for deteriorating items with consideration of optimal production rate and deterioration during delivery", International Journal of Production Economics, 189, pp. 1-13 (2017).

55. Tiwari, S., Jaggi, C.K., Gupta, M., et al. "Optimal pricing and lot-sizing policy for supply chain system with deteriorating items under limited storage capacity", International Journal of Production Economics, 200, pp. 278-290 (2018).

56. Liao, J.J., Huang, K.N., and Chung, K.J. "Lot-sizing decisions for deteriorating items with two warehouses under an order-size dependent trade credit", International Journal of Production Economics, 137, pp. 102115 (2012).

57. Chung, K.J., Cardenas-Barron, L.E., and Ting, P.S. "An inventory model with non-instantaneous receipt and exponentially deteriorating items for an integrated three-layer supply chain system under two levels of trade credit", International Journal of Production Economics, 155, pp. 310-317 (2014).

58. Weskamp, C., Koberstein, A., Schwartz, F., et al. "A two-stage stochastic programming approach for identifying optimal postponement strategies in supply chains with uncertain demand", Omega, 83, pp. 123138 (2019).

59. Tiwari, S., Cardenas-Barron, L.E., Goh, M., et al. "Joint pricing and inventory model for deteriorating items with expiration dates and partial backlogging under two-level partial trade credits in supply chain", International Journal of Production Economics, 200, pp. 16-36 (2018).

60. Puga, M.S., Minner, S., and Tancrez, J.S. "Twostage supply chain design with safety stock placement decisions", International Journal of Production Economics, 209, pp. 183-193 (2019).
61. Modak, N.M. and Kelle, P. "Managing a dual-channel supply chain under price and delivery-time dependent stochastic demand", European Journal of Operational Research, 272, pp. 147-161 (2019).

62. Tiwari, S., Cárdenas-Barrón, L.E., Shaikh, A.A., et al. "Retailer's optimal ordering policy for deteriorating items under order-size dependent trade credit and complete backlogging", Computers and Industrial Engineering, 139, p. 105559 (2020).

63. Adak, S. and Mahapatra, G.S. "Effect of reliability on multi-item inventory system with shortages and partial backlog incorporating time dependent demand and deterioration", Annals of Operations Research, 315, pp. 1551-1571 (2022). DOI: 10.1007/s10479-02003694-6

64. Bhunia, A.K., Shaikh, A.A., Dhaka, V., et al. "An application of genetic algorithm and PSO in an inventory model for single deteriorating item with variable demand dependent on marketing strategy and displayed stock level", Scientia Iranica, 25, pp. 16411655 (2018).

65. Teimoury, E. and Kazemi, S.M.M. "An integrated pricing and inventory model for deteriorating products in a two stage supply chain under replacement and shortage", Scientia Iranica, 24, pp. 342-354 (2017).

\section{Biographies}

Sudip Adak is an Assistant Teacher at Harit High School, Hooghly, West Bengal, India. He is currently a PhD Scholar in NIT Puducherry, India. He obtained MSc degree in Applied Mathematics from Jadavpur University, India. His research interests include inventory control theory, inventory management, interval optimization, operations research, optimization theory, fuzzy systems, etc. He has published six research papers in international/national journals and one chapter in a book.

Ghanshaym S. Mahapatra is an Associate Professor at National Institute of Technology Puducherry, India. He obtained $\mathrm{MSc}$ and $\mathrm{PhD}$ in Applied Mathematics from Bengal Engineering and Science University, Shibpur, presently IIEST Shibpur, India. Dr. Mahapatra has been involved in teaching and research for more than seventeen years and has published more than eighty research articles in various international and national journals and proceedings to his credit. His research interests include inventory management, reliability, optimization, fuzzy set theory, soft computing, and mathematical biology. 